\title{
Relationship between sonographic umbilical cord size and gestational age among preg- nant women in Enugu, Nigeria.
}

\author{
Eze CU¹, Ugwuja MC², Eze CU³ , Agwuna $\mathrm{KK}^{2}$, Ugwu GO4.
}

1. Department of Medical Radiography and Radiological Sciences, Faculty of Health Sciences and Technology, University of Nigeria, Enugu Campus, Enugu State, Nigeria.

2. Department of Radiation Medicine, Faculty of Medicine, University of Nigeria Teaching Hospital, Ituk-Ozalla, Enugu, Enugu State, Nigeria.

3. Department of Radiation Biology, Radiotherapy, Radiodiagnosis and Radiography, Faculty of Clinical Sciences, College of Medicine of the University of Lagos, Idi-Araba, Lagos, Nigeria.

4. Department of Obstetrics and Gynaecology, Faculty of Medicine, University of Nigeria Teaching Hospital Ituku-Ozalla, Enugu, Enugu State, Nigeria.

\begin{abstract}
:
Background: Common fetal parameters for gestational age (GA) estimation have pitfalls especially in advanced pregnancy and pregnancy complicated by fetal structural anomaly.

Objective: To assess the relationship between umbilical cord size and GA of the fetus.

Subjects and Methods: A sonographic cross sectional study involving 300 pregnant women with GA between 14 weeks to 40 weeks was done in Enugu, Nigeria. Gestational ages were first estimated by use of Naegele's formula for GA estimation based on the date of onset of each subject's last menstrual period. Fetal parameters such as biparietal diameter, femur length, head circumference and abdominal circumference were measured and also used to estimate GA. Umbilical cord diameters were measured and used to compute the umbilical cord cross-sectional area.

Results: The mean umbilical cord diameter and cross-sectional area were $14.5 \mathrm{~mm}+7.2 \mathrm{~mm}$ and $201.6 \mathrm{~mm}+139.5 \mathrm{~mm} 2$ respectively. Umbilical cord growth rate of $1.0 \mathrm{~mm} /$ week was noted between the 14th and 35th week of pregnancy. There were significant correlations $(\mathrm{p}<0.001)$ between umbilical cord size and other fetal parameters for GA estimation.

Conclusion: Umbilical cord size had strong linear relationship with common fetal GA estimation parameters and could be used to compliment these parameters for GA estimation.
\end{abstract}

Key words: Sonography, umbilical cord size, gestational age, Nigeria.

DOI: http://dx.doi.org/10.4314/ahs.v14i2.7

\section{Introduction}

Accurate knowledge of the gestational age (GA) is an important determinant of both antenatal care and successful delivery of babies. Gestational age is also a vital factor in the interpretation of biochemical screening tests such as human chorionic gonadotropin (HCG), Alfa feto protein (AFP), estrogen and progesterone levels. Accurate knowledge of these and other maternal serum markers is required in the assessment of fetal

\section{Corresponding Author: \\ Dr. Eze, Charles Ugwoke \\ Department of Medical Radiography \\ and Radiological Sciences, Faculty of \\ Health Sciences and Technology, University \\ of Nigeria, Enugu Campus, Enugu State, Nigeria. \\ Phone: +2348052805214 ; \\ Email: ugwoke.eze@unn.edu.ng ; \\ ezecharlesu@yahoo.com}

anomalies and also in evaluating fetal growth by distinguishing the normal from pathological fetal development.1 This allows obstetricians to institute the best possible antenatal care that may enhance optimal pregnancy outcomes. Furthermore, such important clinical decisions as elective caesarean section (CS) and induction of labour for vaginal delivery often depend on accurate knowledge of the GA.2

Gestation lasts for about 40 weeks (280 days) with the GA being calculated from the first day of onset of the woman's last menstrual period (LMP). Unfortunately, calculation of the GA based on LMP is often inaccurate as many women, especially those with a history of irregular menstrual periods prior to conception, are often unsure of the date of onset of their LMP. Ultrasound (US) imaging is now a commonly used modality to estimate the GA by measuring fetal parameters such as biparietal diameter (BPD), femur length (FL), head circumference $(\mathrm{HC})$, and abdominal circumference (AC). Differences in techniques of measurement tend to diminish the accuracy of US measurement of fetal 
parameters as estimators of GA. Estimation of GA based on BPD in the third trimester of pregnancy, for instance, is generally unreliable because BPD is affected by shape and size of the head.3 Measurement of HC as a predictor of GA compensates for the deficiencies of BPD due to shape of the head but HC measurement often appears technically more difficult and carries a higher degree of observer bias.2 Furthermore, measurement of FL for dating at later stages in pregnancy is considered unreliable as the femur, in some cases, appear foreshortened and therefore, may not give accurate GA in cases of dwarfism. Measurement of AC in the later stage of pregnancy has been touted as the single most important fetal dimension. It is however, more reflective of fetal size/weight than gestational age. In small for date fetuses, for instance, AC may not be a reliable estimator of GA.3

Studies have shown that as pregnancy progresses, the accuracy of fetal parameters as estimators of GA may wax or wane. In the second trimester, for instance, BPD is accurate to GA by +10 days and +21 days in the third trimester. Similarly the FL is accurate to GA by +6 days in the second trimester while in the third trimester, it is accurate to GA by +14 day. 4, 5 However from 20 weeks of gestation, it is more reliable to use the mean values of BPD, FL, HC and AC because the use of a single parameter such as BPD becomes relatively unreliable. A combination of the use of these fetal parameters is known as multiple fetal growth parameters (MFGP).6,7 Since there are drawbacks in the above listed fetal parameters, another parameter for supplementing the GA estimation with minimal error is, therefore, imperative.

Karthikeyan et al,8 Ohagwu et al9 and Nyberg and Finberg10 had, in previous studies, assessed placenta thickness as predictors of GA, and each reported positive correlations between placental thickness (PT) and GA. The umbilical cord is an important feto-maternal unit which contains two arteries and one vein. It modulates blood conveyance between the fetus and placenta. Sonographic assessment of the length, thickness, number of vessels, their diameters, amount of Wharton's jelly, type of placental insertion, coiling and blood flow patterns are some characteristics of the umbilical cord that may reveal increased risk for possible antenatal and pre-natal complications.11 Raio et al12 had, in a previous study, used ultrasound to measure umbilical cord cross-sectional area as an estimator of GA and reported that that umbilical cord cross-sectional area is a more reliable estimator of GA than commonly used fetal parameters for GA estimation. There is paucity of data on the umbilical cord cross-sectional area as a predictor of GA from the local population. It has, however, been established by various studies that there is racial variations in the size and shape of different fetal parameters.13,14 The purpose of the present study is, therefore, to use ultrasound to measure umbilical cord size (diameter and cross-sectional area) among a population of healthy pregnant Nigerian women of Igbo descent in Enugu, Southeast Nigeria, and to determine if there is a correlation between umbilical cord size and gestational age of their fetuses.

\section{Subjects and Methods}

This prospective cross sectional study was carried out between March and October 2012 at University of Nigeria Teaching Hospital (UNTH), Ituku-Ozalla, Enugu. Ethical approval for the study was obtained from UNTH Research and Ethics Committee while informed consents of patients were obtained before the study began.

Purposive sampling method was used to select a sample of 300 subjects from the population of antenatal attendee at the antenatal clinic of UNTH. Inclusion criteria were: singleton gestation, viable fetus, GA (estimated from patient's LMP) of 13 weeks and above, unruptured membranes, and normal amniotic fluid index. Exclusion criteria included: diabetes mellitus, unsure of date, multiple pregnancy, and hypertension of any etiology. The laboratory investigations carried out to exclude diabetes mellitus were urinalysis (sugar), fasting blood sugar, random blood sugar and 2 hours post prandial tests while that of hypertension included urinalysis (protein), serum / electrolyte / urea / creatinine (S/E/U/Cr) and total cholesterol tests.

Scanning technique: Only trans-abdominal sonographic examinations were performed with DP 1100, a high resolution, real time scanner manufactured in 2008 by Shenzhen Mindray Biomedical Electronic Co. Ltd. China, with a $3.5 \mathrm{MHz}$ convex probe. Examinations were carried out with subjects in supine position. All measurements were made on still images captured with the freeze facility of the ultrasound scanner with the on-screen electronic caliper of the ultrasound unit. All sonographic measurements were obtained by an experienced obstetric sonographer with over 20 years experience in obstetric sonography. Commonly measured fetal parameters for GA estimation such as the BPD, FL, HC and AC were all measured following the depart- 
mental protocols for such measurements. Ultrasound estimation of GA was obtained using the algorithm of the scanner based on the formula proposed by Hadlock et al.15 Furthermore, images of the umbilical cord used for measurements were captured only when outer edges of the umbilical cord were outlined in a longitudinal plane. From this plane, the probe is turned to obtain a transverse scan image. Umbilical cord diameters were measured only on the transverse section (figure 1) as described by Ghezzi et al.16 Measurements of the umbilical cord diameter (figure 2), were obtained in a cross sectional plane of the umbilical cord at a point, $2.0 \mathrm{~cm}$ away from point of insertion into the fetal abdomen.17 Diameters obtained from these measurements were used to compute the cross sectional area of the umbilical cord. The GA estimation was based on reliable recollection of the date of onset the last menstrual period (LMP) and the GA calculated from LMP was validated by ultrasound scan done within the first trimester of cyesis.

Data Analysis: Statistical analysis was done using statistical package for social sciences (SPSS) version 17.0, USA. All statistical tests for significance of differences were done at a level of 5\% using two-tailed t-test. Pearson's product moment correlation ( $\mathrm{r}$ ) was used to analyze association of umbilical cord size and other fetal parameters with GA.

\section{Results}

Table 1 shows that the mean umbilical cord diameter is $14.5+7.2 \mathrm{~mm}$ while the mean cord cross-sectional area is $201.6+139.5 \mathrm{~mm} 2$. At 14 weeks of gestation, mean cord diameter was $2.0 \mathrm{~mm}$ while it was $24.2 \mathrm{~mm}$ at 40 weeks. In the same period, mean cord cross-sectional areas were $23.3 \mathrm{~mm} 2$ and $452.4 \mathrm{~mm} 2$ respectively. Tables 2 and 3, and figures 3-6 show that cord diameter appear to increase as GA increased. Tables 2 and 3 also show that umbilical cord size (diameter and cross-sectional area) and other fetal parameters for GA estimation; BPD, FL, HC and AC all increased as pregnancy advanced.

Tables 2 and 3 and figures 7-8 further show that there were linear relationship and statistically significant correlation $(p<0.001)$ between umbilical cord diameter and cross-sectional area with other fetal parameters for gestational age estimation such as; BPD ( $\mathrm{r}=0.95)$; FL $(\mathrm{r}=0.87) ; \mathrm{HC}(\mathrm{r}=0.85) ; \mathrm{AC}(\mathrm{r}=0.83)$, and $\mathrm{BPD}(\mathrm{r}=0.97)$; FL $(r=0.88) ; \mathrm{HC}(\mathrm{r}=0.87)$, and $\mathrm{AC}(\mathrm{r}=0.92)$ for umbilical cord diameter and cross-sectional area respectively.

\section{Discussion}

The attainment of best possible antenatal care and successful pregnancy outcome depends largely on the accurate knowledge of the gestational age (GA). Ultrasound has remained an important imaging modality in estimating GA. Estimation of GA using multiple fetal parameters has been described by many authors.6 Umbilical cord cross-sectional area has been reported in a previous study to be reliable in estimating GA.12

In the present study, we found a mean umbilical cord diameter of $14.5 \mathrm{~mm}$ and a mean cross-sectional area of $201.6 \mathrm{~mm} 2$. This result is only slightly different from the mean umbilical cord diameter of $15 \mathrm{~mm}$ reported in a previous study among Caucasian subjects.18 However, the mean umbilical cord diameter found in the present study is significantly smaller than $20 \mathrm{~mm}$ reported in a Turkish population.19 The mean umbilical cord crosssection area reported in the present study, on the other hand, appears significantly larger than $191 \mathrm{~mm} 2$ reported among Indian subjects. 20 Both umbilical cord diameter and cross-sectional area $(24.3 \mathrm{~mm}$ and $452.4 \mathrm{~mm} 2$ respectively) found at term in the present study, may therefore, be the upper limits of umbilical cord size among the population studied. Causes of these variations were not investigated in the present study. It is likely, however, that variations in the mean of umbilical cord sizes may suggest possible racial or environmental differences in umbilical cord development. Differences noted could also have been due to possible observer bias in the measurements of the cord parameters.

In the present study, the umbilical cord diameter appeared to have increased at the rate of $1 \mathrm{~mm} /$ week from the 14th-30th week of gestation. Mean umbilical cross-sectional area was also found to increase steadily as pregnancy advances. In the present study, both umbilical diameter and its cross-sectional area positively correlated ( $r=0.973$ and $r=0.974$ respectively) with GA. Results of the present study align with those of Togni et al21 who produced normality curves for gestational age estimation using the cross sectional areas of umbilical cord vessels and quantity of Wharton's jelly respectively. In the study, it was reported that umbilical cord cross-sectional area increased as pregnancy advanced. Results of the present study also corroborate those of Weismann and Drugan22 who had earlier reported a strong positive correlation between umbilical cord size (diameter and cross sectional area) and GA. Furthermore, Gehzzi et al16 had equally reported that sonographic cross sectional diameter and area of umbilical cord increased as cyesis advanced while Togni et al21 
had earlier reported a significant correlation between cord cross-sectional area with other fetal anthropometric parameters. The results of present study therefore support earlier opinions suggesting that sonographic measurement of umbilical cord components are important tools for the assessment of fetal growth.

The present study also found that commonly used fetal parameters for sonographic estimation of GA such as BPD, FL, HC and AC all increased as cyesis advanced, and that they all correlated positively with GA. Weismann and Drugan22 and Vasques et al23 had in separate studies, reported strong correlations between commonly used fetal parameters for GA and umbilical cord size. Moreover, Strong et al24 and Gehzzi et al16 also found that sonographic cross sectional diameter and area of umbilical cord increases as pregnancy advanced, and that both (umbilical cord diameter and cross-sectional area) correlated positively with both GA and fetal weight. While it may be plausible to assert that sonographic measurement of umbilical cord size could be used to estimate GA, there is need to compare its accuracy with other commonly used fetal estimators of GA.

The results of the present study, however, showed that umbilical cord diameter and cross sectional area have strong linear relationship with common fetal GA estimation parameters especially between 14 - 35 weeks GA. Before the 14th week and after the 35th week, it appeared that umbilical cord did not increase in size with increase in GA. It appears to suggest that sonographic measurement of umbilical cord size could become an important adjunct when it is certain that other commonly used fetal parameters would be difficult to measure such as in cases of hydrocephalus, anencephalies, dwarfism, and in cases of small for-date fetuses. However, this requires further investigations.

A major limitation of the present study is the small sample size selected which may make results of the study less generally applicable in a country as populous as $\mathrm{Ni}$ geria. Development of GA prediction model using umbilical cord size suitable for the local population could also have improved the quality of the present study.

Conclusion

Umbilical cord size had strong positive correlation with fetal biometric parameters in the population studied. Sonographic measurement of umbilical cord size could be a reliable method of assessing fetal growth and prediction of GA especially between 14 - 35 weeks GA among the population studied.

Conflicts of interest

Authors declare that they have no competing interests.

\section{References}

1. Callen PW; ed. Evaluation of fetal biometry \& abnormal growth. In: Ultrasonography in Obstetrics and Gynecology.5th ed. Philadelphia: Elsevier, a division of Reed Elsevier India limited; 2002.Pp. 225-265.

2. Malhotra N, Kumar P. Measurement of fetal parameters. In: Ultrasound in Obstetrics and Gynecology. 3rd ed. Mumbai: Jaypee Brothers publishers Private Ltd; 1999. Pp.92-98.

3. Lee W, Lee V. L., Kirk J. S Gloan C. T, Smith R S. Vasa Previa: Prenatal diagnosis, Natural evaluation and clinical outcome. Obstetrics Gynecology 2000; 95:577-576.

4. Karki DB, Sharmga UK, Rauniyar RK. Study of accuracy of commonly used fetal parameters for estimation of gestational age. J Nepal Med Assoc.2006; 45(162):233-237.

5. Cromi A. Ghezzi, F Dl Naro, E. Siesto G, Bergamini V. and Raio L. Large cross-sectional area of umbilical cord as a predictor of fetal macrosomia. Ultrasound in Obstetrics and Gynecology 2007; 30: 861866.

6. Chattergee MS, Izquierdo LA, Nevils B, Gilson GJ, Barada C. Fetal foot: evaluation of gestational age. Available at http://www.sonoworld.com/Festus/page. aspx?id=350. Last retrieved on AUG 8, 2013.

7. Predanic M, Pernic SC. Sonographic assessment of the umbilical cord. The Ultrasound Review of Obstetrics and Gynecology 2005; 4(20):105-110.

8. Karthikeyan T, Ramesh KS, Johnson WMS, Prabhu K. Placental thickness and its correlation to gestational age and fetal growth parameters - a cross sectional ultrasonographic study. Journal of Clinical and Diagnostic Research 2012; 6 (10): 1732.

9. Ohagwu CC, Abu PO, Ezeokeke UO, Ugwu AC. Relationship between placental thickness and growth in normal Nigerian fetuses. African Journal of Biotechnology 2009; 8(2): 133-38.

10. Nyberg DA, Finberg HJ. The placenta, placental membranes and umbilical cord. Journal of Diagnostic Ultrasound of Fetal Anomalies 1990; 21 (4):623-27.

11. Bland JM, Altman DG. Statistical method for assessing agreement between two methods of clinical measurements. Ultrasound in Obstetrics and Gynecology 2003;18:121-25.

12. Raio L, Gehzzi F, Di Naro E. Franchi M, Bal- 
esteres D. In-utero characterization of blood flow in hyrtl anastomosis placenta; The Ultrasound Review of Obstetrics and Gynecology 2001; 2:597-607.

13. Charlemaine C, Duyme M, Ville Y, Aurengo A, Tremblay R, Frydman R, Pons JC. Fetal biometric parameters, twin type and birth weight: a longitudinal study. EU J Obstet Gynecol Reprod Biol. 2000; 93(1):27-32.

14. Mastrobattista JM, Pshirrer ER, Hamrick MA, Glaser AM, Schumacher V, Shirkey BA, Wiklund CA, Hollier M. Humerus length evaluation in different ethnic groups. J Ultrasound Med. 2004; 23(2): 227-231.

15. Hadlock FP, Harrist RB, Sharman RS, Deter RL, Park SK. Estimation of fetal weight with the use of head, body, and femur measurements-a prospective study. Am J Obstet Gynecol 1985; 151: 333-337.

16. Gehzzi F, Raio L, Di Nario E, Franchi M, Cromi A. A single and multiple cord cyst in early gestation: two different entities. Ultrasound in Obstetrics and Gynecology 2001; 98:215-219.

17. Masaji U. Ultrasound assessment of abnormal umbilical cord and its circulation. The Ultrasound Review of Obstetrics and Gynecology 2006; 6(3-4): 150156.

18. Collins JH, Collins CL, Collins CC. Umbilical cord accidents (UCAs). Available at www. Preginst. com/puep.htm. Retrieved last on Aug 7,2013.

19. Kiseru DT, Acharya G. The fetal circulation.

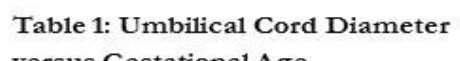

\section{versus Gestational Age}

\begin{tabular}{|c|c|c|}
\hline $\begin{array}{l}\text { Umbilical cord } \\
\text { diameter }(\mathrm{mm})\end{array}$ & $\begin{array}{l}\text { LMP estimated GA } \\
\text { (weeks) }\end{array}$ & n (frequency) \\
\hline 2 & 14 & 10 \\
\hline 3 & 15 & 8 \\
\hline 4 & 16 & 12 \\
\hline 5.0 & 17 & 11 \\
\hline 6.0 & 18 & 9 \\
\hline 7.0 & 19 & 8 \\
\hline 8.0 & 20 & 8 \\
\hline 9.0 & 21 & 9 \\
\hline 10.0 & 22 & 8 \\
\hline 11.0 & 23 & 17 \\
\hline 12.0 & 24 & 10 \\
\hline 13.0 & 25 & 9 \\
\hline 14.0 & 26 & 13 \\
\hline 15.0 & 27 & 16 \\
\hline 16.0 & 28 & 9 \\
\hline 17.0 & 29 & 18 \\
\hline 18.0 & 30 & 11 \\
\hline 19.0 & 31 & 10 \\
\hline 20.5 & 32 & 16 \\
\hline 21.0 & 33 & 9 \\
\hline 21.5 & 34 & 7 \\
\hline 22.0 & 35 & 9 \\
\hline 22.5 & 35 & 12 \\
\hline 23.0 & 37 & 10 \\
\hline 23.5 & 38 & 10 \\
\hline 24.0 & 39 & 12 \\
\hline 24.2 & 40 & 10 \\
\hline Mean: $14.5+7.2$ & & $N=300$ \\
\hline
\end{tabular}

Prenatal Diagnosis 2004; 24(13):1049-1059.

20. Morteza T, Reza A. Evaluation of umbilical cord thickness, cross sectional area, and coiling index as predictors of pregnancy outcome. Indian Journal of Radiology and Imaging 2011; 21(3):195-198.

21. Togni F. A. Araujo E, Fr Vasques, F. A. Amoro, Torlon A. F. Nardozza L. M. The cross sectional area of umbilical cord components in normal pregnancy. International Journal of Gynecology and Obstetrics 2007; 96; 156-161.

22. Weissman A, Drugan A. Sonographic Findings of the umbilical cord implications for fetal chromosomal anomalies Ultrasound Journal of Obstetric and Gynecology 2000; 17: 536-541.

23. Vasques J, Moron AF, Murta CGV, Gonclaves TR, Carvalh FHC. Correlation of umbilical cord cross sectional area and normal anthropometric parameters in normal pregnancies. Radiological Bras 2003;36 (5): 299-303.

24. Strong TH, Elliot JI, Tadim TG. Non-coiled umbilical blood vessels: a new marker for the fetus. Obstet Gynecol 1993; 81:409-411.

Acknowledgements: The authors wish to express their gratitude to Mrs. G. Affam of ANUN Medics Enugu, Nigeria, for her assistance in data collection.

\begin{tabular}{|c|c|c|c|}
\hline 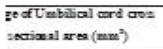 & 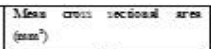 & 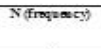 & 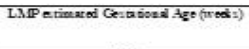 \\
\hline 20 & 235 & 34 & 126 \\
\hline 80 & 352 & 15 & 141 \\
\hline$\overline{00}$ & 443 & 18 & 164 \\
\hline 8.0 & 565 & 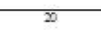 & 180 \\
\hline 50 & 710 & F & 202 \\
\hline 50 & 853 & 15 & 224 \\
\hline 130 & 1040 & 9 & 243 \\
\hline$\overline{1320}$ & 1223 & 15 & 264 \\
\hline 1500 & 1430 & 17 & 285 \\
\hline$\sqrt{1760}$ & 1640 & 18 & 304 \\
\hline 2000 & 1853 & $x$ & 326 \\
\hline 291 & 2126 & I5 & 340 \\
\hline 8501 & 2395 & 15 & 346 \\
\hline 2300 & 2570 & 38 & 359 \\
\hline 8220 & 3025 & \$4 & 380 \\
\hline$\overline{845.0}$ & 3300 & 15 & 383 \\
\hline 590 & 3625 & $\pi$ & 355 \\
\hline$\overline{415: 0}$ & 3975 & 6 & 400 \\
\hline 4500 & 4325 & 11 & 404 \\
\hline \multirow[t]{2}{*}{4525} & 4524 & 13 & 405 \\
\hline & $\operatorname{Man}=2016+1995$ & TOTAL 300 & \\
\hline
\end{tabular}


Table 3: Other fetal Biom etric m easurements versus gestational age

\begin{tabular}{|c|c|c|c|c|c|c|}
\hline $\begin{array}{l}\text { BPD } \\
(\mathrm{mm})\end{array}$ & $\begin{array}{l}\text { FL } \\
(\mathrm{mm})\end{array}$ & $\begin{array}{l}\mathrm{HC} \\
(\mathrm{mm})\end{array}$ & $\begin{array}{l}\text { AC } \\
(\mathrm{mm})\end{array}$ & $\begin{array}{l}\text { Mean GA By } \\
\text { US (weeks) }\end{array}$ & $\begin{array}{c}\mathrm{N} \\
\text { frequency }\end{array}$ & $\begin{array}{l}\text { GA by L.MP } \\
\text { (weeks) }\end{array}$ \\
\hline 28 & 18 & 84 & 80 & 14.6 & 6 & 143 \\
\hline 30 & 20 & 98 & 92 & 15.1 & 9 & 15.0 \\
\hline 32 & 22 & 111 & 103 & 16.4 & 5 & 16.4 \\
\hline 34 & 24 & 124 & 114 & 173 & 6 & 17.5 \\
\hline 36 & 26 & 137 & 126 & 18.4 & 8 & 18.1 \\
\hline 40 & 30 & 162 & 149 & 20.0 & 6 & 202 \\
\hline 42 & 32 & 175 & 160 & 21.0 & 12 & 21.0 \\
\hline 44 & 34 & 186 & 171 & 21.3 & 10 & 21.1 \\
\hline 46 & 36 & 198 & 183 & 22.5 & 6 & 222 \\
\hline 48 & 38 & 210 & 194 & 23.4 & 8 & 232 \\
\hline 50 & 40 & 221 & 206 & 23.4 & 10 & 23.6 \\
\hline 52 & 42 & 231 & 217 & 24.5 & 8 & 24.1 \\
\hline 54 & 44 & 242 & 228 & 24.1 & 6 & 24.4 \\
\hline 56 & 46 & 252 & 240 & 25.0 & 5 & 25.0 \\
\hline 58 & 48 & 261 & 251 & 25.1 & 10 & 25.1 \\
\hline 60 & 50 & 271 & 263 & 26.0 & 12 & 25.6 \\
\hline 62 & 52 & 280 & 214 & 263 & 6 & 263 \\
\hline 64 & 54 & 288 & 285 & 26.6 & 12 & 26.4 \\
\hline 66 & 56 & 296 & 297 & 26.5 & 10 & 263 \\
\hline 68 & 58 & 296 & 308 & 272 & 4 & 27.5 \\
\hline 70 & 60 & 304 & 320 & 28.4 & 8 & 28.4 \\
\hline 72 & 62 & 311 & 331 & 293 & 8 & 242 \\
\hline 74 & 64 & 318 & 342 & 30.1 & 6 & 30.0 \\
\hline 76 & 66 & 324 & 354 & 30.4 & 6 & 30.4 \\
\hline 78 & 68 & 330 & 365 & 30.6 & 10 & 30.5 \\
\hline 80 & 70 & 335 & 377 & 31.4 & 9 & 31.4 \\
\hline 82 & 72 & 340 & 377 & 32.5 & 12 & 32.3 \\
\hline 84 & 74 & 344 & 377 & 33.6 & 6 & 332 \\
\hline 86 & 76 & 344 & 377 & 34.1 & 4 & 343 \\
\hline 88 & 78 & 344 & 377 & 35.4 & 8 & 352 \\
\hline 90 & 80 & 344 & 377 & 36.5 & 10 & 362 \\
\hline 92 & 80 & 344 & 377 & 37.4 & 12 & 37.4 \\
\hline 94 & 80 & 344 & 377 & 38.2 & 6 & 383 \\
\hline 96 & 80 & 344 & 377 & 393 & 8 & 393 \\
\hline 98 & 80 & 344 & 377 & 40.0 & 6 & 402 \\
\hline Total & \multicolumn{6}{|c|}{$\mathrm{N}=300$} \\
\hline
\end{tabular}




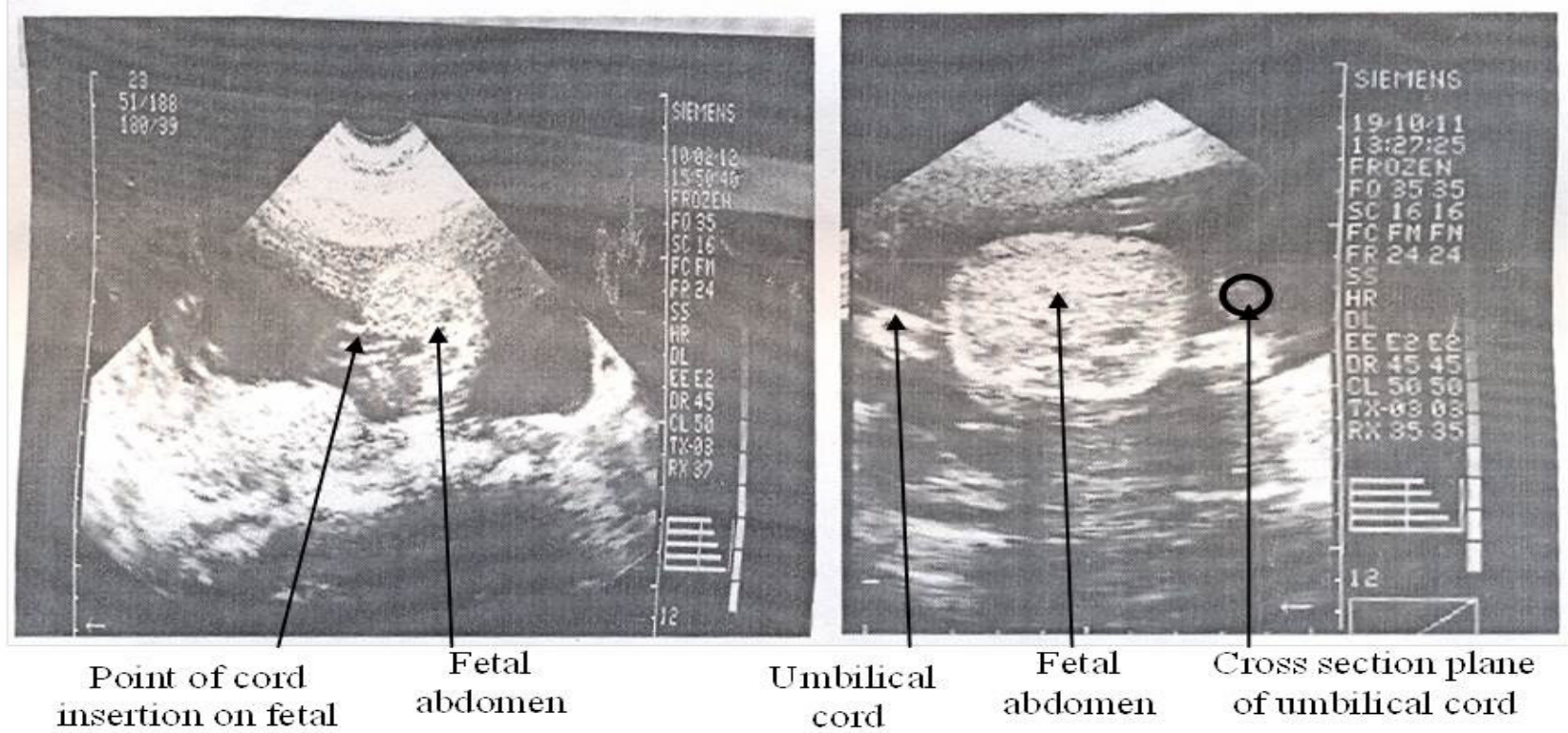
abdomen

Figure 1: Plane for obtaining the cross-sectional Diameter of the umbilical Cord

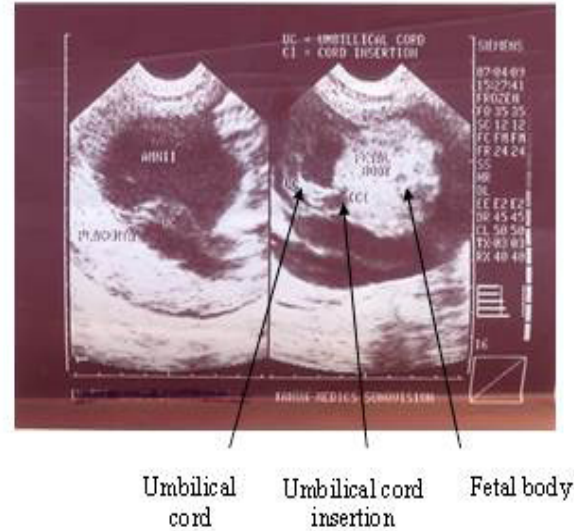

Figure 2: Sonog ram showing umbilical cord insertion into the placenta and fetal abdomen.

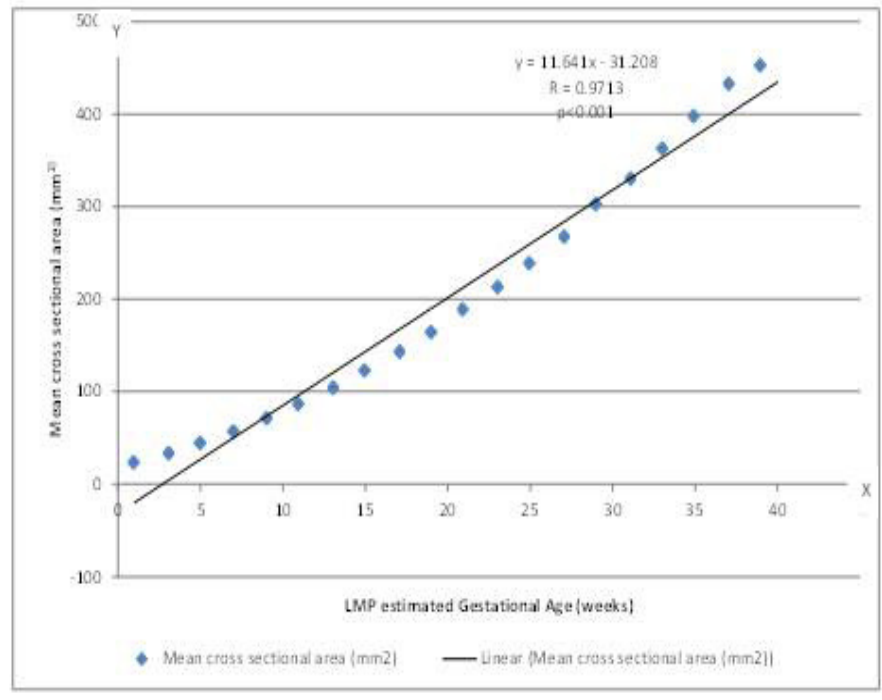

Figure 4: Graph of mean cord cross sectional aea V, GA es timated by LMP

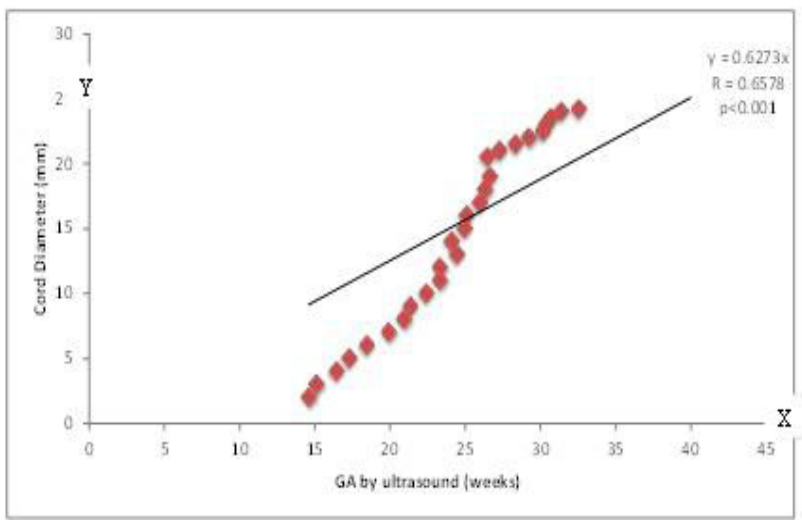

Figure 5: Graph of cord diameter va GA es timated by ultras ound

Figure 3: graph of umbilical cord diameter Vs GA estimated by LMP 


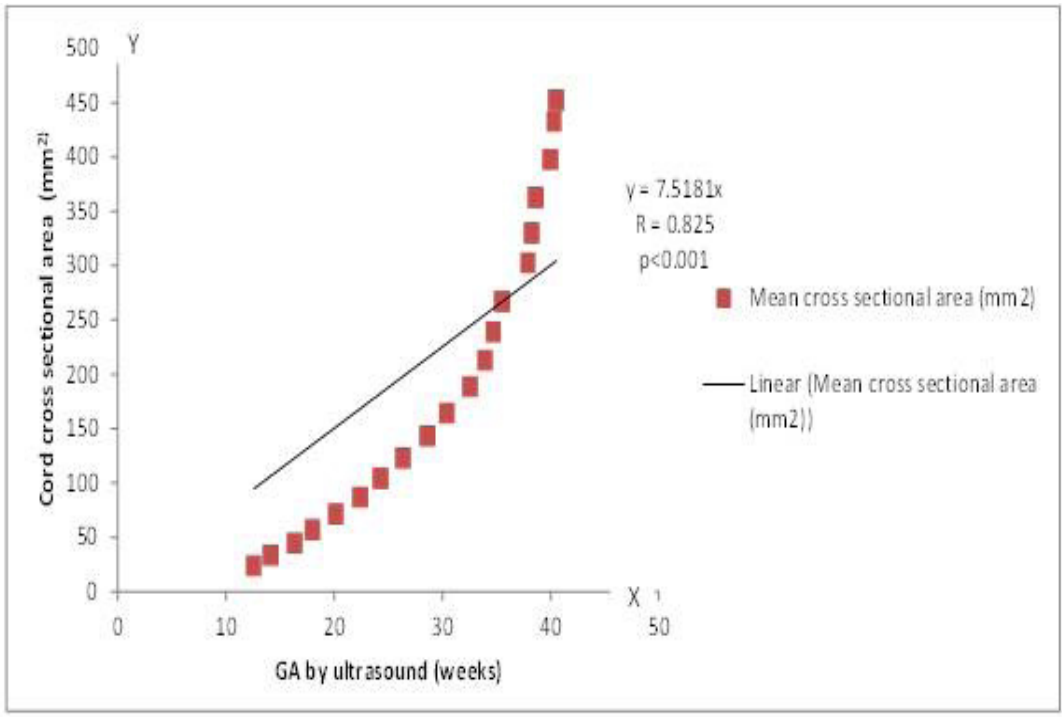

Figure 6: Graph of umbilical cord size Vs GA estimated by Ultrasound

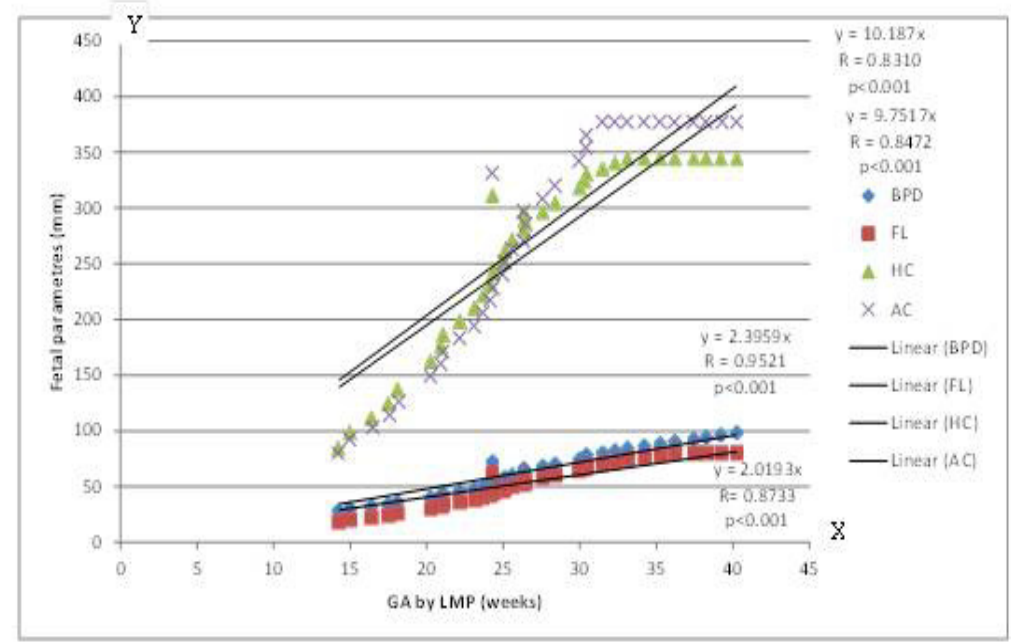

Figure 7: Graph of fetal parameters Vs GA estimated by LMP 


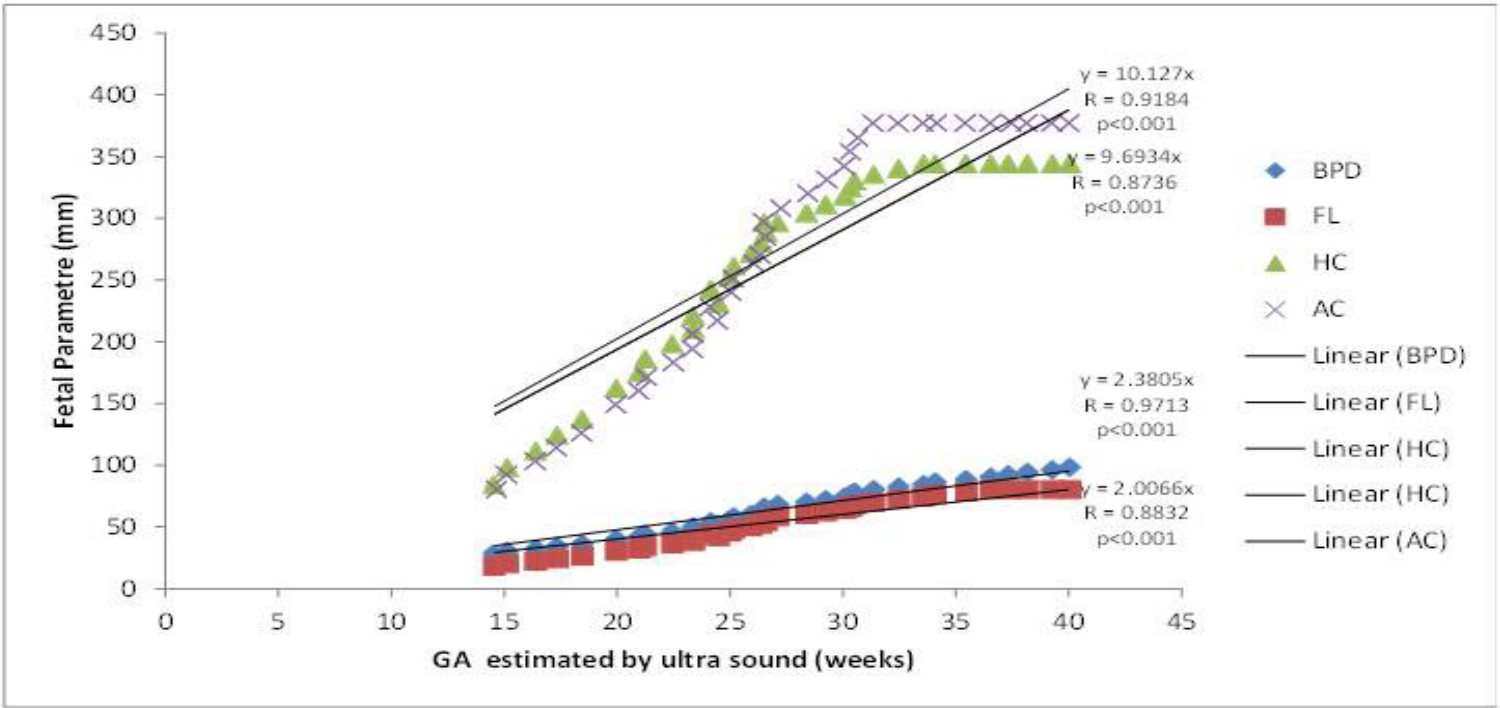

Figure 8: Graph of fetal parameters Vs GA estimated by ultrasound 